\title{
Pengaruh Employee Engagement terhadap Turnover Intention Studi Kasus PT XYZ Bandung
}

\author{
Nida Kania Fauzia*, Marwansyah \\ Jurusan Administrasi Niaga, Politeknik Negeri Bandung
}

\begin{abstract}
:
This research aims to know the level of employee engagement, turnover intention, and influence employee engagement against turnover intention. The methods used in this research is descriptive statistical analysis, while the techniques of data collection using the questionnaire as a primary data and international journals as well as books as the secondary data. Based on the results of the research that has been done, the regression equation is $Y=$ 68,179-0,215X. The results showed that there were negative and significant influence between employee engagement and turnover intention is amount -0.215 and employee engagement affect turnover intention is amount $7.8 \%$.
\end{abstract}

Keywords: absorption, dedication, employee engagement, turnover intention

Pendahuluan

Industri cat di Indonesia semakin meningkatkan daya saingnya agar dapat bersaing di pasar lokal hingga global. Industri ini telah ada sejak dahulu dimana saat ini industri tersebut mengalami perkembangan dengan banyaknya inovasi dan mulai memperhatikan produk yang ramah lingkungan sebagai langkah untuk meningkatkan daya saingnya. Salah satu perusahaan di Indonesia yang memproduksi cat adalah PT XYZ, dimana perusahaan ini dikenal dalam memproduksi cat tembok dengan middle grade hingga low grade. PT XYZ hingga saat ini sudah memiliki 32 cabang di Indonesia dengan pasar yang luas.

Pada setiap perusahaan tenaga kerja menjadi keunggulan kompetitif bagi perusahaan karena karyawan tidak dapat diduplikasi atau ditiru oleh kompetitor. Namun jika terdapat suatu gejala yang dapat menimbulkan masalah menyangkut karyawan, hal ini menjadi titik fokus perusahaan karena perusahaan dapat berjalan dan bertahan, tidak lain dari dukungan karyawan. Salah satu gejala mengenai karyawan yang terdapat di PT XYZ, Bandung adalah adanya peningkatan turnover rate pada dua tahun terakhir. Berikut besarnya turnover rate selama 2 tahun berturut-turut.

Tabel 1. Turnover Rate PT XYZ

\begin{tabular}{|c|c|}
\hline Tahun 2016 & Tahun 2017 \\
\hline $4,28 \%$ & $13,31 \%$ \\
\hline
\end{tabular}

Kemudian didukung juga dengan penyebab keluarnya karyawan dari perusahaan yang ditunjukkan hasil exit interview bulan September 2017-November 2017. Hasilnya adalah sebanyak 38 karyawan keluar secara sukarela (voluntary turnover) dan 6 karyawan keluar secara tidak sukarela (involuntary turnover). Dapat dilihat, jumlah voluntary turnovers lebih banyak dibandingkan involuntary turnover. Dessler (2013) mengatakan bahwa "poor attendance, voluntary turnover, and psychological withdrawal often also reflect diminished employee engagement. Employee engagement is an important 
topic, because many employee behaviors, including turnover, reflect the degree to which employees are engaged".

Seperti yang telah diuraikan di atas, turnover dapat disebabkan oleh kurangnya engagement. Menurut Perez (2008) Turnover is members leaving rather than entering the organization, furthermore the attention was on voluntary turnovers. "Employee engagement as the involvement with and enthusiasm for work" (Gallup Organization dalam Markos dan Sridevi, 2010). Adanya karyawan keluar dengan jumlah yang tinggi dari tahun ke tahunnya, mengindikasikan tingkat rasa keterikatan dengan perusahaannya rendah atau bahkan tidak memiliki rasa keterikatan (disengaged employees). Untuk itu, perusahaan harus dapat mempertahankan karyawannya salah satunya dengan membangun hubungan agar timbul keterikatan pada karyawan.

Berdasarkan pembahasan di atas, maka perlu diketahui bagaimana employee engagement dapat mempengaruhi turnover intention sehingga penelitian yang akan dikaji yaitu mengenai "Pengaruh Employee Engagement terhadap Turnover Intention".

Berdasarkan latar belakang yang telah dijelaskan, berikut perumusan masalah dalam penelitian ini.

1. Bagaimana employee engagement di PT XYZ?

2. Bagaimana turnover intention di PT XYZ?

3. Bagaimana pengaruh employee engagement terhadap turnover intention PT XYZ?

Maksud dari penelitian ini adalah mengetahui pengaruh dari employee engagement terhadap turnover intention di PT XYZ dengan didukung oleh beberapa data yang relevan. Dengan maksud tersebut, maka berikut tujuan penelitian ini.

1. Mengetahui employee engagement di PT XYZ.

2. Mengetahui turnover intention di PT XYZ.

3. Mengetahui pengaruh employee engagement terhadap turnover intention PT XYZ.

\section{Employee Engagement}

Menurut Baumruk (2004), "employee engagement is considered to be the most powerful factor to measure a company's vigour". Selain itu, terdapat pendapat lain menurut Hewitt Associates LLC (dalam J. Anita, 2013) employee engagement didefinisikan sebagai "the state in which individuals are emotionally and intellectually committed to the organisation or group, as measured by three primary behaviours: Say, stay, strive". Berikut ketiga perilaku umum dari engaged employee.

1) Say (Berbicara), karyawan merekomendasikan perusahaan tempatnya bekerja kepada orang lain dan karyawan berbicara positif mengenai perusahaan tempat ia bekerja.

2) Stay (Bertahan), karyawan memiliki komitmen dan loyal pada perusahaan meskipun memiliki kesempatan untuk bekerja di perusahaan lain dan berkeinginan untuk menjadi bagian dari organisasi.

3) Strive (Bekerja keras), karyawan dapat mengerjakan pekerjaan melebihi apa yang diperintahkan oleh perusahaan untuk berkontribusi pada kesuksesan perusahaan dan menggunakan waktu, usaha, juga inisiatif yang lebih untuk berkontribusi penuh pada perusahaan.

Pada awalnya konsep employee engagement ditemukan oleh Kahn pada 1990 dalam jurnal "Psychological conditions of personal engagement and disengagement at work" yang mengungkapkan bahwa "the harnessing of organization members' selves to their work roles; in engagement, people employ and express themselves physically, cognitively, and emotionally during role performances". Penelitian lainnya dilakukan oleh (Schaufeli et al, 2002) yang mendefinisikan employee engagement as a positive, fulfilling, work-related state of mind that is characterized by vigor, dedication, and absorption. (Schaufeli dan Bakker, 2004) menyimpulkan terdapat tiga dimensi employee engagement, diantaranya vigor, dedication, dan absorption.

Vigor dinilai oleh enam hal yang menunjukkan tingginya energi dan ketahanan, kerelaan untuk berusaha, tidak mudah lelah, dan ketekunan dalam menghadapi kesulitan. Mereka yang memiliki nilai tinggi pada vigor biasanya memiliki banyak energi, semangat dan stamina saat bekerja.

Dedication dinilai oleh lima hal yang mengacu pada pentingnya pekerjaan seseorang, merasa antusias dan bangga dengan pekerjaannya, dan merasa terinspirasi dan tertantang oleh pekerjaannya. Mereka yang berprestasi tinggi dalam dedikasi, mengidentifikasikan dirinya dengan pekerjaannya karena hal itu dialami dan dianggap sebagai sesuatu yang bermakna, inspiratif, dan menantang. Selain 
itu, mereka biasanya merasa antusias dan bangga dengan pekerjaan mereka. Mereka yang memiliki nilai rendah, tidak mengidentifikasi dirinya dengan pekerjaannya karena mereka tidak mengalaminya dan menjadi bermakna, tidak terinspirasi, atau menantang, tidak antusias atau bangga dengan pekerjaan mereka.

Absorption diukur dengan enam hal yang mengacu pada totalitas, karyawan "tenggelam" dalam pekerjaan dan mengalami kesulitan memisahkan diri dari pekerjaan sehingga waktu berlalu dengan cepat dan seseorang melupakan hal lain yang ada di sekitarnya. Mereka yang memiliki nilai tinggi pada absorption biasanya senang dengan pekerjaan mereka, mereka merasa "tenggelam" oleh pekerjaan dan memiliki kesulitan untuk melepaskannya. Sebagai konsekuensinya, segala sesuatu lainnya yang ada di sekitar dilupakan dan waktu tidak terasa berjalan dengan cepat. Mereka yang memiliki nilai absorption rendah tidak merasa senang atau "tenggelam" dalam pekerjaan mereka, mereka tidak memiliki kesulitan untuk melepaskan diri darinya, juga tidak melupakan segala sesuatu di sekitar mereka, termasuk waktu. Menurut Bakker (2008), terdapat empat dampak employee engagement terhadap engaged employee diantaranya experience positive emotions, experience better health, ability to mobilize resources, dan crossover of engagement. Menurut Baumruk (2006), terdapat lima kunci untuk meningkatkan employee engegement yang dapat dipraktikan dimana hal ini dibutuhkan peran manajer atau atasan adalah adanya pelatihan karyawan, memberikan penghargaan, memberikan kejelasan mengenai ekspektasi kinerja, libatkan karyawan dalam pengambilan keputusan dan eksekusi, dan menjalin hubungan yang baik.

\section{Turnover Intention}

Menurut Price (1977), turnover is the movement of members accross the boundary of an organization. Sedangkan turnover menurut Perez (2008) adalah members leaving rather than entering the organization, furthermore the attention was on voluntary turnovers. Lebih lanjut lagi Perez mengemukakan bahwa voluntary turnover has relevant implications for organizational manpower planning. Manpower planning itu sendiri didefinisikan sebagai perencanaan jumlah tenaga kerja yang dibutuhkan oleh suatu perusahaan sehingga penting bagi perusahaan untuk menganalisis dan mengukur tingkat turnover intention. Turnover berbeda dengan turnover intention. Seperti yang dinyatakan oleh Chang (2008) bahwa the turnover intention is the psychology or thought process before generating the turnover behavior. Menurut Roodt (2004) turnover intention memiliki satu dimensi yaitu intenion to leave or stay.

Menurut Perez (2008) terdapat tiga dampak turnover yaitu organizational cost, operational disruption, dan demoralization of organizational membership. Organizational cost adalah biaya untuk uang pesangon, administratif yang terkait dengan penghentian, dan tentunya biaya juga waktu untuk melakukan exit interview (separation cost). Untuk menggantikan posisi karyawan yang keluar, perusahaan harus mengeluarkan biaya untuk melakukan rekruitmen dengan memasang iklan lowongan kerja dan interview karyawan masuk (replacement cost). Tidak hanya itu, dibutuhkan biaya untuk melakukan training karyawan baru (training cost). Operational disruption adalah gangguan operasional terjadi ketika tingginya tingkat ketergantungan peran kerja pada perusahaan. Adanya karyawan yang keluar, perusahaan harus menempatkan karyawan lain untuk mengisi posisi kosong karena hal tersebut. Namun yang dapat menjadi masalah adalah ketika belum ada karyawan yang mampu untuk mengerjakan pekerjaan posisi tersebut sehingga perusahaan harus melakukan back up. Demoralization of organizational membership adalah adanya hal yang dapat memicu sentimen dengan karyawan lain yang masih bertahan di perusahaan, seperti mempertanyakan mereka mengenai motivasi apa yang membuat mereka dapat bertahan di perusahaan.

Perusahaan dapat mengendalikan tingkat turnover intention yang tinggi dengan melakukan strategi retensi. Strategi ini merupakan cara bagaimana perusahaan dapat mempertahankan karyawannya agar tidak keluar dari perusahaan, bahkan dapat menciptakan rasa loyal pada karyawan itu sendiri. Dessler (2013) mengemukakan mengenai retention strategy for reducing voluntary turnover. Kemudian menurut Development Dimensions International (DDI) dan the employment firm Robert Half International dalam Dessler (2013) menyarankan untuk membangun program retensi yaitu.

1. Selection. Retensi dimulai dari proses seleksi dengan memilih calon karyawan yang tepat.

2. Professional growth. Program pelatihan dan pengembangan karir yang dipikirkan dengan baik dapat memberikan insentif yang kuat bagi karyawan untuk tetap bertahan perusahaan. Seperti yang dikatakan seorang ahli, para profesional yang merasa perusahaannya peduli dengan 
perkembangan dan kemajuan, mereka akan jauh lebih mungkin untuk bertahan pada perusahaan.

3. Provide career direction. Komunikasikan secara berkala mengenai karir dan prospek kepada karyawan, dan membantunya untuk menyusun rencana karir yang potensial.

4. Meaningful work and ownership of goals. Karyawan tidak dapat melakukan pekerjaan mereka jika tidak tahu apa yang harus dilakukan atau apa tujuannya. Oleh karena itu, bagian penting dari mempertahankan karyawan adalah dengan memberikan kejelasan mengenai apa saja yang menjadi tanggung jawab mereka.

5. Recognition and rewards. Karyawan membutuhkan pengakuan dan dihargai atas pekerjaan yang dilakukannya dengan baik. Manajer dapat memberikan pujian atas hasil pekerjaan karyawannya dan rewards berupa beasiswa pendidikan atau bonus.

6. Culture and environment. Perusahaan yang sangat tegang dan politis bisa membuat karyawannya keluar, sementara perusahaan yang membuat mereka merasa nyaman mendorong mereka untuk tinggal.

7. Promote work-life balance. Dalam satu survei yang dilakukan oleh Robert Half dan careerbuilder.com, mengidentifikasi pengaturan kerja yang fleksibel dan telecommuting sebagai dua manfaat utama yang akan mendorong karyawan untuk memilih satu pekerjaan atau pekerjaan lain.

8. Acknowledge achievements. Ketika karyawan merasa kurang dihargai, mereka cenderung keluar. Survei menunjukkan bahwa pengakuan terhadap prestasi sering merupakan hadiah nonmoneter yang efektif.

Berdasarkan tujuan penelitian, perumusan masalah dan kerangka pemikiran di atas, dapat dilihat hipotesis penelitian ini yaitu.

$\mathrm{H}_{0}$ : Tidak terdapat pengaruh negatif yang signifikan employee engagement terhadap turnover intention di PT XYZ.

$\mathrm{H}_{\mathrm{a}}$ : Terdapat pengaruh negatif yang signifikan employee engagement terhadap turnover intention di PT XYZ.

\section{Metode Penelitian}

Objek penelitian ini mengenai perilaku organisasi yang berfokus pada employee engagement dan turnover intention dengan jumlah responden 144 karyawan PT XYZ, Bandung.

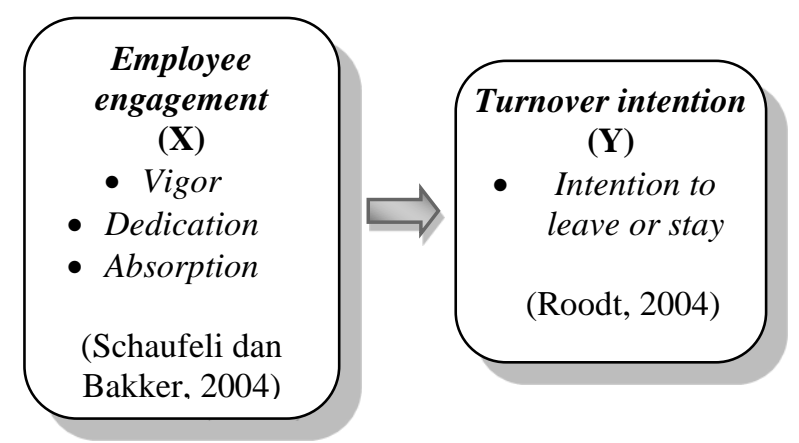

Gambar 1. Kerangka Pemikiran

Metode yang digunakan dalam penelitian ini adalah metode deskriptif dengan pendekatan kuantitatif karena dalam pelaksanaanya meliputi data berupa angka yang diolah menggunakan analisis statistik yang kemudian dijelaskan secara deskriptif dengan tujuan untuk menguji hipotesis yang telah ditetapkan. Metode ini bertujuan untuk mengukur pengaruh variabel employee engagement terhadap variabel turnover intention.

Variabel employee engagement diukur dengan menggunakan instrumen UWES (Utrech Work Engagement Scale) dan untuk mengukur variabel turnover intention menggunakan TIS (Turnover Intention Scale). Populasi karyawan PT XYZ, Bandung sebesar 667 karyawan terhitung hingga Maret tahun 2018. Sample yang digunakan sebesar 144 karyawan, teknik pengambilan sample menggunakan 
quota sampling. Data primer yang digunakan berasal dari kuesioner dan data sekunder berasal dari jurnal internasional serta buku.

Menurut Indrawati (2015), butir-butir pernyataan dalam kuesioner merupakan instrumen (alat) ukur yang harus mengukur apa yang menjadi tujuan penelitian. Karena itu tiap butir pernyataan dalam kuesioner harus diukur validitasnya. Selain valid, instrumen pun harus reliabel seperti yang dinyatakan oleh Arikunto (2010), reliabilitas menunjuk pada satu pengertian bahwa sesuatu instrumen cukup dapat dipercaya untuk digunakan sebagai alat pengumpul data. Sebelum melakukan penyebaran kuesioner kepada seluruh responden penelitian, dibutuhkan pengujian mengenai instrumen yang valid dan reliabel kepada 30 responden. Jika hasil pengolahan data 30 responden tersebut memiliki validitas yang melebihi $r$ tabel $(0,3061)$ dan reliabilitas yang dan lebih dari 0,6, maka kuesioner tersebut dapat digunakan dan disebar kepada seluruh responden penelitian. Jika instrumen telah valid dan reliabel kemudian data diuji dengan menggunakan statistik deskriptif, uji korelasi sederhana, uji regresi linier sederhana, uji hipotesis, dan koefisien determinasi.

\section{Hasil dan Pembahasan}

Demografi Responden

Data demografi respoden ditunjukkan pada tabel 2.

Tabel 2. Data Demografi Responden

\begin{tabular}{|c|c|c|c|}
\hline Demografi & Keterangan & Jumlah & $\%$ \\
\hline Jenis & Laki-laki & 97 & 67,4 \\
\cline { 2 - 4 } Kelamin & Perempuan & 47 & 32,6 \\
\hline \multirow{4}{*}{ Usia } & $21-25$ tahun & 16 & 11,1 \\
\cline { 2 - 4 } & $26-30$ tahun & 41 & 28,5 \\
\cline { 2 - 4 } & $31-35$ tahun & 35 & 24,3 \\
\cline { 2 - 4 } & $36-40$ tahun & 35 & 24,3 \\
\cline { 2 - 4 } & $41-45$ tahun & 11 & 7,6 \\
\cline { 2 - 4 } & $>45$ tahun & 6 & 4,2 \\
\hline \multirow{4}{*}{$\begin{array}{c}\text { Pendidikan } \\
\text { Terakhir }\end{array}$} & SMA/ SMK & 33 & 22,9 \\
\cline { 2 - 4 } & D1/D2/D3 & 34 & 23,6 \\
\cline { 2 - 4 } & S1/D4 & 74 & 51,4 \\
\cline { 2 - 4 } & S2 & 3 & 2,1 \\
\hline \multirow{4}{*}{ Masa Kerja } & $<5$ tahun & 52 & 36,1 \\
\cline { 2 - 4 } & $6-10$ tahun & 41 & 28,5 \\
\cline { 2 - 4 } & $11-15$ tahun & 23 & 16 \\
\cline { 2 - 4 } & $>15$ tahun & 28 & 19,4 \\
\hline
\end{tabular}

\section{Hasil Uji Validitas dan Reliabilitas}

Hasil uji validitas variabel employee engagement pada 30 karyawan dinyatakan valid dengan pearson correlation > 0,3061 dan hasil uji validitas variabel employee engagement pada 144 karyawan dinyatakan valid dengan pearson correlation $>0,1367$.

Hasil uji validitas variabel turnover intention pada 30 karyawan dinyatakan valid dengan pearson correlation > 0,3061 dan hasil uji validitas variabel turnover intention pada 144 responden, hasil uji validitas pada 144 responden dinyatakan valid dengan pearson correlation $>0,1367$.

Hasil uji reliabilitas variabel employee engagement pada 144 karyawan sebesar 0,760 dan hasil uji reliabilitas variabel turnover intention pada 144 karyawan sebesar 0,726. Nilai Cronbach's Alpha kedua vaiabel tersebut berada pada interval 0,6-0,79, dikatakan reliabilitas atau konsistesi dari kuesioner tersebut diterima.

\section{Analisis Deskriptif}

Hasil analisis statistik deskriptif employee engagement ditunjukkan pada tabel 3.

Tabel 3. Statistik Deskriptif Variabel Employee Engagement 


\begin{tabular}{|c|c|c|c|c|c|}
\hline & $\mathrm{N}$ & Min. & Max. & Mean & Std. Dev \\
\hline Vigor & 144 & 0 & 6 & 4,00 & 1,193 \\
\hline Dedication & 144 & 2 & 6 & 5,12 & 1,047 \\
\hline Absorption & 144 & 1 & 6 & 3,45 & 1,238 \\
\hline Employee engament & 144 & 0 & 6 & 4,19 & 1,159 \\
\hline Valid N (listwise) & 144 & & & & \\
\hline
\end{tabular}

Berdasarkan tabel 3, variabel employee engagement memiliki 3 dimensi yaitu vigor, dedication, dan absorption. Mean variabel employee engagement sebesar 4,00. Jika dilihat pada tabel interpretasi hasil analisis deskriptif, variabel employee engagement berada di interval 3,63-4,83 yang termasuk ke dalam kategori tinggi. Pada variabel employee engagement, dimensi dedication memiliki mean tertinggi sebesar 5,12 dan dimensi absorption memiliki mean terendah sebesar 3,45. Jawaban tertinggi dari setiap dimensi adalah 6, sedangkan jawaban terendah pada setiap dimensi berbeda-beda. Dimensi vigor, dedication, dan absorption masing-masing memiliki jawaban terendah sebesar 0,2 , dan 1 . Nilai standar deviasi variabel employee engagement sebesar 28,9\% (1,159/4,00 X 100\%). Nilai tersebut berada di atas $20 \%$ yang menunjukkan bahwa jawaban responden cukup beragam.

Hasil analisis statistik deskriptif turnover intention ditunjukkan pada tabel .

Tabel 4. Statistik Deskriptif Variabel Turnover Intention

\begin{tabular}{|c|c|c|c|c|c|}
\hline & $\mathrm{N}$ & Min. & Max. & Mean & Std. Dev \\
\hline Intention to leave or stay & 144 & 1 & 7 & 3,85 & 1,564 \\
\hline Valid N (listwise) & 144 & & & & \\
\hline
\end{tabular}

Berdasarkan tabel 4, variabel turnover intention memiliki 1 dimensi yaitu intention to leave or stay. Mean variabel turnover intention sebesar 3,85. Jika dilihat pada tabel interpretasi hasil analisis deskriptif, dimensi intention to leave or stay berada di interval 3,42-4,62 yang termasuk ke dalam kategori sedang. Jawaban tertinggi dari dimensi tersebut adalah 7 , sedangkan jawaban terendahnya adalah 1. Nilai standar deviasi variabel turnover intention sebesar 40,6\% (1,564/3,85 X 100\%). Nilai tersebut berada di atas $20 \%$ yang menunjukkan bahwa jawaban responden cukup beragam.

\section{Uji Korelasi Sederhana}

Hasil uji korelasi sederhana ditunjukkan pada tabel 5.

Tabel 5. Hasil Uji Korelasi Sederhana

\begin{tabular}{|l|l|c|c|}
\hline \multicolumn{2}{|c|}{} & Employee Engagement & Turnover Intention \\
\hline \multirow{3}{*}{ Employee Engagement } & Pearson Correlation & 1 &,$- 279^{* *}$ \\
\cline { 2 - 4 } & Sig. (2-tailed) & &, 001 \\
\cline { 2 - 4 } & $N$ & 144 & 144 \\
\hline \multirow{3}{*}{ Turnover Intention } & Pearson Correlation &,$- 279^{* *}$ & 1 \\
\cline { 2 - 4 } & Sig. (2-tailed) &, 001 & 144 \\
\cline { 2 - 4 } & $N$ & 144 & \\
\hline \multirow{2}{*}{$* *$ Correlation is significant at the 0.01 level (2-tailed). } \\
\hline
\end{tabular}

Berdasarkan tabel 5, output menunjukkan nilai signifikansi sebesar $0,001<0,05$ yang memiliki arti nilai tersebut signifikan. Nilai korelasi variabel employee engagement dan turnover intention sebesar -0,279. Apabila melihat dari interpretasi menurut Arikunto (2010), nilai tersebut berada di sekitar koefisien korelasi -1, maka mengindikasikan korelasi negatif yang disertai perubahan dalam arah berbeda. Hasil interpretasi koefisien korelasi memiliki tingkat hubungan yang rendah yang berada pada interval 0,20-0,399. 


\section{Uji Regresi Linier Sederhana}

Berdasarkan nilai signifikansi dari tabel 7 , diperoleh nilai signifikansi sebesar $0,001<0,05$, sehingga dapat disimpulkan bahwa variabel employee engagement berpengaruh terhadap turnover intention. Hasil output pada tabel 7, diketahui nilai constant (a) sebesar 68,179, sedangkan nilai employee engagement (b) sebesar $-0,215$, sehingga persamaan regresinya sebagai berikut.

$\mathrm{Y}=\mathrm{a}+\mathrm{bX}$

$\mathrm{Y}=68,179-0,215 \mathrm{X}$

Koefisien sebesar 68,179, mengandung arti bahwa nilai konstanta variabel turnover intention sebesar 68,179 . Koefisien regresi $X$ sebesar $-0,215$ memiliki arti bahwa setiap penambahan $1 \%$ nilai employee engagement, maka nilai Turnover Intention akan berkurang sebesar -0,215. Koefisien regresi tersebut bernilai negatif, yang mengandung arti employee engagement berpengaruh negatif terhadap turnover intention.

Tabel 6. Hasil Uji Regresi Linier Sederhana

\begin{tabular}{|c|c|c|c|c|c|c|}
\hline \multicolumn{7}{|c|}{ Coefficients $^{\mathbf{a}}$} \\
\hline \multirow{2}{*}{ Model } & \multicolumn{2}{|c|}{ Unstand. Coefficients } & Std. Coefficients & \multirow{2}{*}{ Sig. } \\
\cline { 3 - 5 } & B & Std. Error & Beta & & \\
\hline \multirow{2}{*}{1} & (Constant) & 68,179 & 4,202 & & 16,224 &, 000 \\
\cline { 2 - 7 } & Engagement &,- 215 &, 062 &,- 279 & $-3,461$ &, 001 \\
\hline \multicolumn{7}{|c|}{ a. Dependent Variable: Turnover Intention } \\
\hline
\end{tabular}

\section{Uji Hipotesis}

Pada penelitian ini, uji hipotesis yang digunakan adalah uji-T dan Uji-F.

Tabel 7. Hasil Uji T

\begin{tabular}{|c|c|c|c|c|c|c|}
\hline \multicolumn{7}{|c|}{ Coefficients $^{\mathbf{a}}$} \\
\hline \multirow{2}{*}{ Model } & Unstand. Coefficients & Std. Coefficients & \multirow{2}{*}{ S } & \multirow{2}{*}{ Sig. } \\
\cline { 3 - 5 } & B & Std. Error & Beta & &, 000 \\
\hline \multirow{2}{*}{1} & (Constant) & 68,179 & 4,202 & & 16,224 &, 001 \\
\cline { 2 - 5 } & Engagement &,- 215 &, 062 &,- 279 & $-3,461$ &, 00 \\
\hline \multicolumn{7}{|c|}{ a. Dependent Variable: Turnover Intention } \\
\hline
\end{tabular}

Berdasarkan hasil output pada tabel 8, nilai signifikansi $\mathrm{t}_{\text {hitung }}$ sebesar -3,461 dengan significance level 0,05 dan df: $(\mathrm{n}-\mathrm{k})=142$, diperoleh $\mathrm{t}_{\text {tabel }}$ sebesar 1,65566, maka interpretasi dari hasil $-\mathrm{t}_{\text {tabel }}>\mathrm{t}_{\text {hitung }}$ $(-1,65566)>-3,461)$ sehingga $\mathrm{H}_{\mathrm{a}}$ diterima dan $\mathrm{H}_{0}$ ditolak.

Tabel 8. Hasil Uji F

\begin{tabular}{|l|l|l|l|l|}
\hline \multicolumn{5}{|c|}{ ANOVA $^{\text {a }}$} \\
\hline \multicolumn{2}{|c|}{ Model } & \multicolumn{1}{|c|}{ Df } & \multicolumn{1}{c|}{ F } & \multicolumn{1}{c|}{ Sig. } \\
\hline \multirow{3}{*}{1} & Regression & 1 & 11,977 &, $001^{\text {b }}$ \\
\cline { 2 - 5 } & Residual & 142 & & \\
\cline { 2 - 5 } & Total & 143 & & \\
\hline \multicolumn{2}{|l|}{ a. Dependent Variable: Turnover Intention } \\
\hline
\end{tabular}

Berdasarkan hasil output pada tabel 9, nilai signifikansi $\mathrm{F}_{\text {hitung }}$ sebesar 11,977 dengan significance level 0,05 dan df1: $(\mathrm{k}-1)=1$, df2: $(\mathrm{n}-\mathrm{k})=142$, diperoleh $\mathrm{F}_{\text {tabel }}$ sebesar 3,91, maka interpretasi dari hasil tersebut $\mathrm{F}_{\text {hitung }}>\mathrm{F}_{\text {tabel }}(11,977>3,91)$ sehingga $\mathrm{H}_{\mathrm{a}}$ diterima dan $\mathrm{H}_{0}$ ditolak. 
Tabel 9. Hasil Koefisien Determinasi

\begin{tabular}{|c|c|c|c|c|}
\hline \multicolumn{5}{|c|}{ Model Summary } \\
\hline Model & $\mathrm{R}$ & R Square & Adjusted R Square & Std. Error of the Estimate \\
\hline 1 &, $279^{\mathrm{a}}$ &, 078 &, 071 & 10,566 \\
\hline
\end{tabular}

Dapat dilihat pada tabel 10, diperoleh koefisien determinasi ( $R$ Square) sebesar 0,078, yang memiliki pengertian bahwa pengaruh variabel bebas (employee engagement) terhadap variabel terikat (turnover intention) adalah sebesar 7,8\%, sedangkan 92,2\% dipengaruhi oleh faktor-faktor lain yang tidak menjadi variabel pada penelitian ini.

\section{Pengaruh Employee Engagement terhadap Turnover Intention}

Berdasarkan hasil penelitian pada 144 karyawan PT XYZ, Bandung, dapat diketahui bahwa terdapat hubungan negatif antara employee engagement dan turnover intention. Hal tersebut didukung oleh hasil uji korelasi sederhana yang menunjukkan nilai signifikansi sebesar $0,001<0,05$ yang memiliki arti bahwa nilai tersebut signifikan dan nilai korelasi variabel employee engagement dan turnover intention sebesar $-0,279$. Tanda minus menunjukkan adanya korelasi negatif yang disertai perubahan dalam arah berbeda.

Berdasarkan hasil uji regresi linier sederhana diketahui bahwa terdapat pengaruh negatif employee engagement terhadap turnover intention. Hal ini dapat dilihat dari nilai signifikansi sebesar 0,001 yang kurang dari 0,05 dan besarnya pengaruh employee engagement terhadap turnover intention sebesar 0,215 dengan persamaan regresi $\mathrm{Y}=68,179-0,215 \mathrm{X}$. Koefisien sebesar 68,179, mengandung arti bahwa nilai konstanta variabel turnover intention sebesar 68,179. Koefisien regresi X sebesar $-0,215$ memiliki arti bahwa setiap penambahan $1 \%$ nilai employee engagement, maka nilai turnover intention akan berkurang sebesar $-0,215$.

Hasil uji hipotesis pada uji $\mathrm{T}$ dan uji $\mathrm{F}$ menunjukkan bahwa menerima $\mathrm{H}_{\mathrm{a}}$ dan menolak $\mathrm{H}_{0}$ yang berarti terdapat pengaruh negatif antara employee engagement dan turnover intention. Pada uji $\mathrm{T}$, nilai signifikansi thitung sebesar -3,461 dengan significance level 0,05 dan df: $(\mathrm{n}-\mathrm{k})=142$, diperoleh $\mathrm{t}_{\text {tabel }}$ sebesar 1,65566, maka interpretasi dari hasil tersebut $\left.-t_{\text {tabel }}>t_{\text {hitung }}(-1,65566)>-3,461\right)$ sehingga $H_{a}$ diterima dan $\mathrm{H}_{0}$ ditolak. Nilai $\mathrm{t}_{\text {hitung }}$ negatif menunjukkan bahwa variabel employee engagement memiliki hubungan yang berlawanan arah dengan variabel turnover intention. Selain itu, uji $\mathrm{F}$ menunjukkan nilai signifikansi $\mathrm{F}_{\text {hitung }}$ sebesar 11,977 dengan significance level 0,05 dan df1: $(\mathrm{k}-1)=1$, df2: $(n-k)=142$, diperoleh $F_{\text {tabel }}$ sebesar 3,91, maka interpretasi dari hasil tersebut $F_{\text {hitung }}>F_{\text {tabel }}(11,977$ $>3,91)$ sehingga $\mathrm{H}_{\mathrm{a}}$ diterima dan $\mathrm{H}_{0}$ ditolak.

Jika dilihat hasil koefisien determinasi, menunjukkan ( $R$ Square) sebesar 0,078, yang memiliki pengertian bahwa pengaruh employee engagement terhadap turnover intention adalah sebesar 7,8\%, sedangkan $92,2 \%$ dipengaruhi oleh faktor-faktor lain yang tidak menjadi variabel pada penelitian ini. Faktor-faktor lain yang dapat mempengaruhi turnover intention adalah job stress, job satisfaction, dan oranizational commitment (Lambert, 2016). Pendapat lain (Price, 2001) menyatakan dalam modelnya bahwa job involvement, job stress, pay, promotional chances, dan general training berpengaruh pada turnover intention.

Employee engagement merupakan salah satu variabel yang dapat menurunkan tingkat turnover intention (Lu et.al, 2016). Ketika karyawan engaged dengan perusahaan, kemungkinan karyawan untuk keluar dari perusahaan akan kecil. Hasil penelitian ini menunjukkan adanya pengaruh yang negatif antara employee engagement dan turnover intention. Berdasarkan hasil statistik analisis, employee engagement PT XYZ, Bandung termasuk kategori tinggi. Hal tersebut dapat disebabkan oleh faktor usia,dimana semakin bertambahnya usia karyawan maka akan lebih engaged seperti yang dinyatakan oleh (Schaufeli\&Bakker, 2004: 18). Usia dapat dikelompokkan menjadi generasi atau gen. Hlongwane\&Ledimo (2015) dalam penelitiannya menyimpulkan bahwa tingkat employee engagement berbeda-beda tergantung pada generation group. Menurut Zemke et.al (2000), generation group terbagi menjadi 4 yaitu veterans (1922-1943), baby boomers (1944-1960), generation X (1961 - 1980), 
generation Y (1981-2000). Jika dilihat, karyawan PT XYZ, Bandung dikategorikan ke dalam 3 generasi yaitu baby boomers (6 karyawan), generation X (46 karyawan), generation Y (92 karyawan). Tingkat employee engagement yang memiliki mean tertinggi yaitu pada baby boomers sebesar 4,89 yang termasuk dalam kategori sangat tinggi, generation X memiliki mean sebesar 3,96 yang termasuk dalam kategori tinggi, dan tingkat employee engagement terendah yaitu pada generation $\mathrm{Y}$ sebesar 3,82 yang termasuk dalam kategori tinggi. Meskipun ketiganya termasuk ke dalam kategori sangat tinggi dan tinggi, namun hal ini membuktikan bahwa semakin bertambahnya usia, karyawan semakin engaged. Selain usia, jenis kelamin berpengaruh pada tingkat employee engagement seperti yang dinyatakan oleh Banihani, et.al (2013: 401) bahwa work engagement lebih mudah bagi laki-laki untuk terlibat secara fisik, kognitif dan emosional daripada wanita dalam organisasi. Hal ini terbukti mayoritas karyawan PT XYZ, Bandung berjenis kelamin laki-laki dengan jumlah 97 karyawan dan sisanya 47 karyawan perempuan. Meskipun hasilnya termasuk kedalam kategori tinggi, namun terdapat beberapa section yang memiliki mean dimensi absorption, vigour, dan dedication yang berada pada kategori sedang sehingga perusahaan harus dapat mengambil langkah yang tepat untuk meningkatkan ketiga dimensi tersebut. Hal tersebut perlu ditingkatkan agar niat karyawan untuk keluar dari perusahaan menjadi rendah yang kemudian berdampak pada biaya operasional perusahaan. Sementara itu, tingkat turnover intention PT XYZ, Bandung termasuk dalam kategori sedang. Makna dari kategori sedang adalah sebagian besar karyawan memiliki niat untuk keluar dari perusahaan namun masih terdapat kemungkinan karyawan akan tetap bertahan jika harapan karyawan dapat terpenuhi oleh perusahaan. Semakin terpenuhinya harapan karyawan dapat mempengaruhi tingkat turnover yang dipengaruhi oleh keterikatan karyawan organisasi secara psikologi (Shaw et.al, 1998). Terdapat beberapa section yang memiliki tingkat turnover intention yang sedang yaitu transport, warehouse, HC, TMIS, SCM, desgin, employee relation, procurement, inventory, product support, WB, MIS IT, TAX, R\&D $1, R \& D 2$, engineering service, $R \& D 3$, dan non WB. Sementara itu, terdapat satu section yang memiliki turnover intention kategori tinggi yaitu colour group. Jika dihubungkan dengan variabel employee engagement, beberapa section tersebut memiliki dimensi absorption, dedication, dan vigour dalam kategori sedang. Hal inilah yang dapat menjadi fokus bagaimana agar karyawan dapat semakin engaged dan tingkat turnover intention semakin rendah. Seperti yang dinyatakan oleh Baumruk (2006) bahwa semakin tinggi tingkat engagement, employee turnover akan menurun dan hal itu akan membantu perusahaan mencapai kinerja perusahaan lebih baik. Hasil penelitian ini selaras dengan penelitian yang dilakukan Lu et.al (2016) dan penelitian Saks (2006) bahwa work engagement berpengaruh negatif terhadap turnover intention.

\section{Kesimpulan dan Saran}

Berdasarkan hasil analisis dan pembahasan yang telah dipaparkan, tingkat employee engagement PT $\mathrm{XYZ}$, Bandung berada pada kategori tinggi. Dimensi yang memiliki mean terendah yaitu absorption dan dimensi yang memiliki mean tertinggi yaitu dedication. Dimensi vigour berada pada kategori tinggi, dimensi dedication berada pada kategori sangat tinggi, dan dimensi absorption berada pada kategori sedang. Namun terdapat beberapa section yang memiliki mean dalam kategori sedang pada dimensi vigor yaitu section transport, color group, WB, R\&D 2, R\&D 3, dan colour group, section yang memiliki mean dalam kategori sedang pada dimensi dedication yaitu colour group dan R\&D 3, dan section yang memiliki mean dalam kategori rendah pada dimensi absorption yaitu colour group. Tingkat turnover intention PT XYZ, Bandung berada pada kategori sedang. Dimensi intention to leave or stay berada pada kategori sedang. Employee engagement berpengaruh negatif terhadap turnover intention sebesar 7,8\%, sedangkan 92,2\% dipengaruhi oleh faktor-faktor lain yang tidak menjadi variabel pada penelitian ini.

Untuk itu, terdapat beberapa masukan untuk perbaikan bagi perusahaan, yaitu:

1. Peningkatan dimensi absorption. Peran manajer sangat penting dalam meningkatkan semangat karyawan agar tumbuh rasa senang dalam bekerja secara sungguh-sungguh sehingga akan meningkatkan konsentrasi karyawan. Selain itu, lingkungan kerja (meliputi hubungan manager dan staff, sesama rekan kerja) harus dapat mendukung agar karyawan merasa nyaman dalam bekerja sehingga dapat berkonsentrasi dengan baik menyelesaikan pekerjaannya.

2. Peningkatan dimensi dedication pada section colour group dan R\&D 3. Untuk meningkatkan hal tersebut, manajer harus memberikan penjelasan mengenai pentingnya dan tujuan tugas 
serta tanggung jawab section colour group dan R\&D 3 agar karyawan menganggap tugas dan tanggung jawabnya menantang sehingga terpacu untuk lebih semangat dan fokus dalam bekerja.

3. Peningkatan dimensi vigor pada section R\&D 2, R\&D 3, colour group, transport, dan WB. Untuk meningkatkan hal tersebut, peran manajer atau atasan dapat memberikan motivasi kepada karyawan dan melakukan workplace exercise seperti stretching di pertengahan jam kerja agar karyawan tidak mudah lelah saat bekerja.

4. Tingkat Turnover Intention pada PT XYZ, Bandung berada pada kategori sedang. Untuk mempertahankan karyawannya, perusahaan dapat melakukan strategi retensi dengan mengadakan pelatihan dan pengembangan karir yang dapat memberikan insentif yang kuat bagi karyawan untuk tetap bertahan perusahaan, manajer berperan langsung dalam membantu karyawan untuk menyusun rencana karir yang potensial, dan memberikan penghargaan atas hasil kerja karyawan berupa beasiswa pendidikan.

\section{Daftar Pustaka}

Arikunto, S. (2010). Prosedur Penelitian Suatu Pendekatan Praktik. Jakarta: PT Rineka Cipta.

Baumruk, R. (2004). The missing link: the role of employee engagement in business success, Workspan, 47 (11):. 48-52.

Baumruk, R. (2006). Why Managers are Crucial to Increasing Engagement. An interview by Bob Gorman Jr., Robert E. Gorman Communication. Melcrum Publishing, Ltd.

Chang, C. (2008). Internal Marketing Practices and Employees Turnover Intentions In Leisure Hotels. The Journal of Human Resource and Adult learning, 4 (2).

Dessler, G. (2013). Human Resources Management (Thirteenth Edition). United States: Pearson Education, Inc., publishing as Prentice Hall.

Hlongwane, V., Ophillia, L. (2015). Generational Differences On Work Engagement Levels Of Government Heathcare Institution Employees. Journal Of Governance And Regulation, 4 (1).

Indrawati. (2015). Metode Penelitian Manajemen dan Bisnis Konvergensi Teknologi Komunikasi dan Informasi. Bandung: Refika Aditama.

J, Anita. (2013). Determinants of employee engagement and their impact on employee performance. International Journal of Productivity and Performance Management, 63 (3): 308-323.

Kahn, W.A. (1990). Psychological Conditions of Personal Engagement and Disengagement at Work, Academy of Management Journal, 33 (4): 692-724.

Markos, S., Sandhya, M. (2010). Employee Engagement: The Key to Improving Performance, International Journal of Business and Management, 5 (12).

Perez, M. (2008). Turnover Intent. University of Zurich, Strategie- und Unternehmensökonomik.

Price, J. (2001). Reflections on the Determinants of Voluntary Turnover. International Journal of Manpower, 22 (1): 600-624.

Roodt, G., Bothma, F.C. (2004). The Validation of the Turnover Intention Scale. SA Journal of Human Resource Management, 12 (1).

Schaufeli, W.B., Salanova, M., Gonza'lez-Roma', V. and Bakker, A.B. (2002). The Measurement of Engagement and Burnout: A Two Sample Confirmatory Factor Analytic Approach, Journal of Happiness Studies, 3 (1): 71-92.

Schaufeli, W.B., Bakker, A.B. (2004). UWES - Utrecht Work Engagement Scale: Test Manual, Department of Psychology, Utrecht University. Preliminary Manual [Version 1.1, December 2004].

Zemke R., Claire, R., Bob, F. (2000). Generations at Work: Managing the Clash of Veterans, Boomers, Xers and Nexters in Your Workplace. Soundview Executive Book Summaries, 22 (4).

\section{*Email korespondensi:}

Nida Kania Fauzia

nidakania@gmail.com 